\title{
Immature Testicular Teratoma
}

National Cancer Institute

\section{Source}

National Cancer Institute. Immature Testicular Teratoma. NCI Thesaurus. Code C6353.

An immature teratoma that arises from the testis. 